\title{
Risk Factors for Otitis Media in Children Referred to Abuzar Hospital in Ahvaz: A Case-Control Study
}

Amir Kamal Hardani ${ }^{1}$, Fatemeh Moghimi Esfandabadi ${ }^{1}$, Maryam Delphi ${ }^{2}$, Mohsen Ali Samir ${ }^{1}$, Farzaneh Zamiri Abdollahi ${ }^{3}$

1. Department of Pediatrics, Faculty of Medicine, Abuzar Children's Hospital, Ahvaz Jundishapur University of Medical Sciences, Ahvaz, IRN 2. Department of Audiology, Musculoskeletal Rehabilitation Research Center, Ahvaz Jundishapur University of Medical Sciences, Ahvaz, IRN 3. Department of Audiology, School of Rehabilitation, Tehran University of Medical Sciences, Tehran, IRN

Corresponding author: Maryam Delphi, delphi.maryam1@gmail.com

\section{Abstract}

\section{Introduction}

Otitis media is one of the most common causes of infection in preschool children. The most damaging complication of otitis media is temporary or permanent hearing loss. This study aimed to determine the important risk factors for otitis media.

\section{Methods}

In this case-control study, 625 children aged six months to seven years were examined from winter to spring 2020 , and 53 children with otitis media were allocated to the case group and the same number to the control group. The chi-square test was used to identify the risk factors affecting otitis media, and the risk factors were compared between the case and control groups. Logistic regression was used to investigate the relationship between the incidence of otitis media and risk factors.

\section{Results}

Bivariate analysis revealed the following primary risk factors for otitis media: using pacifiers or bottle feeding, working mother, seasonal rhinitis, allergic rhinitis, tonsillopharyngitis, rhinorrhea, and adenoid hypertrophy $(\mathrm{P}<0.05)$. In logistic regression analysis, using pacifiers or bottle feeding (odds ratio $[\mathrm{OR}]=0.156$, $\mathrm{P}=0.000)$, working mother $(\mathrm{OR}=0.226, \mathrm{P}=0.000)$, seasonal rhinitis $(\mathrm{OR}=0.175, \mathrm{P}=0.000)$, allergic rhinitis $(\mathrm{OR}=5.20, \mathrm{P}=0.000)$ and adenoid hypertrophy $(\mathrm{OR}=1.57, \mathrm{P}=0.000)$ were identified as the most important risk factors.

\section{Conclusion}

Received 08/03/2020

Review began 08/04/2020 Review ended 08/06/2020 Published 08/15/2020

\section{() Copyright 2020}

Hardani et al. This is an open access article distributed under the terms of the Creative Commons Attribution License CC-BY 4.0., which permits unrestricted use, distribution, and reproduction in any medium, provided the original author and source are credited.
Adenoid hypertrophy and allergic rhinitis increased the risk of otitis media more than the other risk factors. Therefore, pediatricians should increase their awareness of the existence of these risk factors in a patient, and take the appropriate diagnostic steps and implement therapeutic care to prevent language and speech complications.

Categories: Otolaryngology, Pediatrics, Quality Improvement

Keywords: otitis media, risk factor, allergic rhinitis, adenoid hypertrophy

\section{Introduction}

Otitis media, which is inflammation of the middle ear, is one of the more common childhood disorders that can lead to hearing loss. Approximately two-thirds of children of all ages are affected by otitis media [1]. Various studies have reported it having a prevalence of $15 \%$ to $40 \%[2,3]$.

According to the World Health Organization, approximately 42 million people over the age of three years suffer hearing loss due to otitis media [4]. Approximately $90 \%$ of children experience this disorder before they enter the school system. Many attacks of otitis media spontaneously resolve within three months, but in $30 \%$ to $40 \%$ of children, the disorder becomes recurrent $[5,6]$. Otitis media occurs in $75 \%$ of children at least three times in their first three years of life [7].

Otitis media is caused by bacteria, fungi, or viruses, and sometimes follows other infections, such as respiratory infections. One of the leading causes of otitis media is eustachian tube dysfunction. The eustachian tube may be blocked due to neoplasm, enlarged adenoids, inflammatory factors, and sinusitis, all of which cause fluid to build up in the middle ear [8]. 
Otitis media is seen in three forms: acute, chronic, and with effusion [9]. Antibiotics are often administered, and surgery is often performed during childhood because of otitis media. High direct and indirect costs have been estimated for otitis media, which can be a significant economic burden on health [10]. Furthermore, there are no specific guidelines in developing countries for antibiotic use for otitis media or upper respiratory tract infections. In some of these countries, the appropriate antibiotics to use are available over the counter in pharmacies [2].

The risk factors for ear infections are cultural, socioeconomic, and environmental (e.g., living in crowded places, living in large families, the duration of breastfeeding, smoking status), genetic (e.g., craniofacial anomalies such as those characteristic in Down syndrome and cleft palate), nutritional, and medical (e.g., age, gender, race, health status, history of several acute otitis episodes, rhinorrhea, allergic rhinitis, seasonal rhinitis, snoring, upper respiratory tract infections, and adenoid hypertrophy) [10-13]. No strong correlation has yet been found between otitis media and smoking, breastfeeding, or socioeconomic status [6,14]. However, some recent studies have challenged these proven factors [3,13].

Although otitis media may be asymptomatic, it can be detected during audiometric tests with temporary conductive hearing loss or by using Type B tympanometry. However, complications may exist, such as delayed language and speech, ruptured eardrum, cholesteatoma, and reading and writing impairment [15]. Other complication is mastoiditis, meningitis, acute labyrinthitis, acute petrositis. Mastoiditis is the most common intratemporal complication, and meningitis is the most commonly seen intracranial complication [16].

In developing countries, purulent infections, including chronic infections of the middle ear, mastoiditis, meningitis, cerebral abscess, infectious diseases, and epidural abscess, are essential complications of untreated middle ear infections. According to statistics, approximately 20,000 children under age five die each year from the untreated complications of otitis media [16].

Considering the above, additional consideration should be given to the rapid diagnosis and treatment of this infection and the elimination of contributing factors [17]. Therefore, due to the high prevalence of otitis media in children and its effect on hearing, speech, language, and cognitive status of children, it is necessary to study the risk factors and control them. This study aimed to investigate the factors that increase the chance of otitis media in children aged six months to seven years who were referred to Abuzar Children's Hospital by comparing the risk factors in the case and control groups.

\section{Materials And Methods}

This case-control, cross-sectional study was conducted from winter to spring of 2020 with children aged six months to seven years with otitis media who were treated at Abuzar Hospital of Ahvaz, Iran. Considering the $7 \%$ prevalence of otitis media in children, $80 \%$ power and $5 \%$ test error with a sample size of 53 children per group was calculated.

There were 625 children aged six months to seven years who were referred by pediatricians and pediatric asthma and allergy subspecialists to the Hearing Clinic of Abuzar Hospital. After receiving consent from their parents, hearing assessments began. The children first underwent otoscopy and tympanometry. Among the patients, 53 children with Type B tympanogram and healthy ear canal volume and otoscopic findings indicating the presence of otitis media (acute, chronic, and with effusion) were included in the case group. A pediatrician was consulted to confirm the diagnosis of otitis media. Then, the otitis media risk factor checklist was completed for them. Also, 53 children with Type A tympanogram normal hearing and normal otoscopy were included in the control group from among the children referred to the Abuzar Hearing Clinic. The checklist was also completed for these children.

The data collection tool was a checklist with three sections consisting of demographic information, audiology results, and otitis media risk factors. Based on previous studies, the following risk factors were extracted and studied: age, gender, working mother, education, large family, smoking, using pacifiers or bottle feeding, rhinorrhea, snoring, allergic rhinitis, seasonal rhinitis, tonsillopharyngitis, and adenoid hypertrophy $[6,12]$.

A Reister ${ }^{\circledR}$ otoscope was used for otoscopy, and an AZ26 tympanometer was used for tympanometry. A pediatric asthma and allergy subspecialist determined the types of rhinitis and made the diagnoses of enlarged adenoids or tonsillopharyngitis. The risk factor of a large family was defined as a family with more than four members [13]. Children with impacted cerumen, Down syndrome, cleft palate, or systemic diseases such as diabetes, nephrotic syndrome, and immunodeficiency were excluded because they are susceptible to respiratory tract infections.

In addition to using descriptive statistics of the mean and standard deviation, in the data analysis, the chisquare test was used to examine the bivariate association between each of the 13 risk factors and otitis media and to compare the case and control groups. Multivariate logistic regression analysis was also used for variables obtained at a significance level of less than 0.05 in the bivariate analysis. The tests were 


\section{Cureus}

considered significant at 0.05 . The data were analyzed using IBM SPSS Statistics for Windows, Version 22.0 (IBM Corp., Armonk, NY).

\section{Results}

Table 1 separately shows the demographic characteristics of the two groups. The mean age of the subjects in the case and control groups was $40.52 \pm 20.39$ and $36.03 \pm 18.12$ months, respectively, with no significant difference between them $(\mathrm{P}=0.609)$. As Table 1 shows, there was no significant difference between the two age groups in terms of age, sex, or education. However, the percentage of working mothers was higher in the case group $(\mathrm{P}=0.011)$.

\begin{tabular}{|c|c|c|c|c|c|c|}
\hline \multicolumn{2}{|l|}{ Variable } & \multicolumn{2}{|l|}{ Case } & \multicolumn{2}{|l|}{ Control } & \multirow[t]{2}{*}{$P$-value } \\
\hline & & Number & Percent & Number & Percent & \\
\hline \multirow{5}{*}{ Age } & $>2$ years & 18 & 34 & 16 & 30.0 & 0.91 \\
\hline & $2-3$ & 15 & 28.3 & 17 & 32.1 & 0.91 \\
\hline & $3-4$ & 8 & 15.1 & 11 & 2.8 & 0.62 \\
\hline & $4-5$ & 6 & 11.3 & 4 & 7.5 & 0.79 \\
\hline & $>5$ & 6 & 11.3 & 5 & 9.4 & 0.83 \\
\hline \multirow{2}{*}{ Sex } & Female & 28 & 52.8 & 26 & 49.1 & \multirow{2}{*}{0.65} \\
\hline & Male & 25 & 47.2 & 27 & 50.9 & \\
\hline \multirow{2}{*}{ Education } & Literate & 46 & 86.8 & 45 & 84.9 & \multirow{2}{*}{0.780} \\
\hline & Illiterate & 7 & 13.2 & 8 & 15.1 & \\
\hline \multirow{2}{*}{ Occupation } & Employed & 29 & 54.7 & 16 & 30.2 & \multirow{2}{*}{0.011} \\
\hline & Unemployed & 24 & $45 / 3$ & 37 & 69/8 & \\
\hline
\end{tabular}

TABLE 1: Distribution of demographic characteristics in the two groups

Table 2 shows the distribution of risk factors in the case and control groups. Risk factors with a significance level of less than 0.05 in the bivariate analysis were included in the logistic regression analysis. These variables included: using pacifiers or bottle feeding, working mother, seasonal rhinitis, allergic rhinitis, tonsillopharyngitis, adenoid hypertrophy, and rhinorrhea. 


\section{Cureus}

\begin{tabular}{|c|c|c|c|c|c|}
\hline \multirow{2}{*}{ Risk Factor } & \multicolumn{2}{|l|}{ Case } & \multicolumn{2}{|l|}{ Control } & \multirow{2}{*}{ P-value } \\
\hline & Number & Percent & Number & Percent & \\
\hline Use of a pacifier or bottle & 39 & $73 / 6$ & 20 & $37 / 7$ & 0.000 \\
\hline Smoking & 24 & $45 / 3$ & 28 & $52 / 8$ & 0.437 \\
\hline Seasonal rhinitis & 40 & $75 / 4$ & 16 & $30 / 2$ & 0.000 \\
\hline Allergic rhinitis & 37 & $71 / 7$ & 24 & $45 / 3$ & 0.011 \\
\hline Tonsillopharyngitis & 25 & $47 / 2$ & 12 & $22 / 6$ & 0.008 \\
\hline Adenoid hypertrophy & 38 & 71/1 & 15 & $28 / 3$ & 0.000 \\
\hline Vaccination & 50 & $94 / 3$ & 52 & $98 / 1$ & 0.308 \\
\hline Large family & 32 & $60 / 4$ & 28 & $52 / 8$ & 0.433 \\
\hline Persistent rhinorrhea & 30 & $56 / 6$ & 8 & $15 / 1$ & 0.006 \\
\hline Low weight & 23 & $53 / 4$ & 18 & 34 & 0.319 \\
\hline Snoring & 22 & $41 / 5$ & 15 & $28 / 3$ & 0.154 \\
\hline
\end{tabular}

TABLE 2: Distribution of otitis media risk factors in the two groups

Of the children with otitis media, $73.6 \%$ had a history of using pacifiers or bottle feeding, which was significantly different from the control group ( $\mathrm{P}=0.000$ ). As Table 2 shows, $75.4 \%$ of children with otitis had seasonal rhinitis, $71.7 \%$ had allergic rhinitis, $47.2 \%$ had tonsillopharyngitis, $71.7 \%$ had adenoid hypertrophy, and $56.6 \%$ had rhinorrhea, and these were significantly different from those of the control group. No correlation was observed between the incidence of otitis media and other risk factors $(\mathrm{P}>0.05)$.

Logistic regression analysis was performed to investigate the simultaneous effect of the mentioned variables on the incidence of otitis media. According to the logistics model, with 50\% confidence, the risk of developing otitis media was predictable by using five risk factors of pacifiers or bottle feeding, seasonal rhinitis, allergic rhinitis, adenoid hypertrophy, and working mother. The results of logistic regression showed that using pacifiers or bottle feeding, seasonal rhinitis, allergic rhinitis, adenoid hypertrophy, and working mothers are significant risk factors for otitis media.

According to Table 3, the first risk factor that has the greatest impact on the incidence of otitis media is allergic rhinitis, such that children with allergic rhinitis are 5.20 times more likely to develop otitis media. Also, children with adenoid hypertrophy are 1.15 times more likely to develop otitis media. Risk factors of seasonal rhinitis, using pacifiers, and working mothers were also significant in the logistics model, indicating the impact of these factors on the incidence of otitis media.

\begin{tabular}{|c|c|c|c|}
\hline Risk Factor & Odds Ratio & $95 \%$ Confidence Interval & P-value \\
\hline Allergic rhinitis & 5.20 & $(1.06-25.46)$ & 0.000 \\
\hline Adenoid hypertrophy & 1.157 & $(0.04-4 / 58)$ & 0.000 \\
\hline Use of a pacifier or bottle & 0.156 & $(0.05-0.58)$ & 0.000 \\
\hline Seasonal rhinitis & 0.175 & $(0.04-0.65)$ & 0.000 \\
\hline Occupation & 0.226 & $(0.07-0.67)$ & 0.000 \\
\hline
\end{tabular}

TABLE 3: Logistic regression analysis results in examining otitis media risk factors

\section{Discussion}

In the present study, we found no significant relationship between the incidence of otitis media and demographic characteristics such as age, gender, and educational level. This was consistent with a cohort 
study by Telee et al., but contrary to the findings of a study by Sophia et al. that emphasized the role of gender and age in the incidence of otitis media $[5,6]$.

The results of the present study showed that allergic rhinitis has a significant relationship with the incidence of otitis media such that allergic rhinitis increases the risk of otitis media by 5.20 times. This was confirmed in a study by Norhafizah et al. that examined the link between allergic rhinitis and otitis media and reported that the prevalence of allergic rhinitis in otitis media was $80 \%$. Dust particles were the most common cause of allergies [18]. This finding has been confirmed in other studies [6,19].

The results showed that adenoid hypertrophy is one of the main causes of otitis media such that adenoid hypertrophy increases the risk of otitis media by 1.15 times. In a study on 2602 children, Kumari et al. identified adenoid hypertrophy as the most important risk factor for otitis media [4]. This was also found in a study by Amani and Khazraie [20].

The present study found a significant relationship between absolute breastfeeding and otitis media, which is consistent with a cohort study by Telee et al. in Boston [5]. Seasonal rhinitis was another risk factor for otitis media in the present study. This finding has also been proven in previous studies [6]. Another risk factor examined in the present study was working mothers, which was significantly different between the case and control groups and was one of the predictors of otitis media incidence. This finding has not been studied before. Rhinorrhea and tonsillopharyngitis risk factors were not significantly different between the two groups, which is similar to studies by Kumari et al. and Sophia et al. [4,6]. However, according to the logistic regression model, these factors were not predictors of otitis media in children.

This study found no link between family size and otitis media, but in the Norhafizah et al. study, the presence of more than four family members was a risk factor for otitis [18]. When comparing the two groups, there was no significant difference in other examined factors, including smoking, low birth weight, snoring, and vaccination. This may be due to the small sample size when examining the above factors. A study by Lubianca et al. also did not show a significant relationship between cigarette smoke and the incidence of otitis media [21]. Additionally Sophia et al. showed a link between snoring and the incidence of otitis media [6].

One of the limitations of this study was the small sample size and the time-consuming nature of examining all risk factors in all patients during the research period.

\section{Conclusions}

Although pacifiers and bottle feeding, seasonal rhinitis, allergic rhinitis, adenoid hypertrophy, working mother, and rhinorrhea are among the risk factors for otitis media, allergic rhinitis and adenoid hypertrophy are two risk factors that are stronger predictors of otitis media. Therefore, pediatricians should increase their awareness of the existence of these risk factors in a patient and consider all risk factors in otitis media for appropriate diagnostic and therapeutic measures to prevent the complications of otitis media such as speech, language, and cognitive delay.

\section{Additional Information}

\section{Disclosures}

Human subjects: Consent was obtained by all participants in this study. Ahvaz Jundishapur University of Medical Sciences issued approval IR.AJUMS.REC.1399.030. The project was found to be in accordance to the ethical principles and the national norms and standards for conducting Medical Research in Iran. Notice: 1. Although the proposal has been approved by the research ethics committee, meeting the professional and legal requirement is the sole responsibility of the PI and other project collaborators. 2 . This certificate is reliant on the proposal/documents received by this committee on 2020-04-11. The committee be notified by the PI as soon as the proposal/document are modified. . Animal subjects: All authors have confirmed that this study did not involve animal subjects or tissue. Conflicts of interest: In compliance with the ICMJE uniform disclosure form, all authors declare the following: Payment/services info: All authors have declared that no financial support was received from any organization for the submitted work. Financial relationships: All authors have declared that they have no financial relationships at present or within the previous three years with any organizations that might have an interest in the submitted work. Other relationships: All authors have declared that there are no other relationships or activities that could appear to have influenced the submitted work.

\section{Acknowledgements}

This article was extracted from a research project (IR.AJUMS.REC.1399.030) approved by the Research Ethics Deputy of Ahvaz Jundishapur University of Medical Sciences. The authors hereby thank the physicians at the Abuzar Children's Hospital for their contribution.

\section{References}


1. Todberg T, Koch A, Andersson M, Olsen SF, Lous J, Homoe P: Incidence of otitis media in a contemporary Danish National Birth Cohort. PLoS One. 2014, 9:111732. 10.1371/journal.pone.0111732

2. DeAntonio R, Yarzabal JP, Cruz JP, Schmidt JE, Kleijnen J: Epidemiology of otitis media in children from developing countries: a systematic review. Int J Pediatr Otorhinolaryngol. 2016, 85:65-74. 10.1016/j.ijporl.2016.03.032

3. Abrahams SW, Labbok MH: Breastfeeding and otitis media: a review of recent evidence . Curr Allergy Asthma Rep. 2011, 11:508-512. 10.1007/s11882-011-0218-3

4. Kumari MS, Madhavi J, Krishna NB, Meghanadh KR, Jyothy A: Prevalence and associated risk factors of otitis media and its subtypes in South Indian population. Egyptian J ENT Allied Sci. 2016, 17:57-62. 10.1016/j.ejenta.2016.04.001

5. Teele DW, Klein JO, Rosner B: Epidemiology of otitis media during the first seven years of life in children in greater Boston: a prospective, cohort study. J Infect Dis. 1989, 160:83-94. 10.1093/infdis/160.1.83

6. Sophia A, Isaac R, Rebekah G, Brahmadathan K, Rupa V: Risk factors for otitis media among preschool, rural Indian children. Int J Pediatr Otorhinolaryngol. 2010, 74:677-683. 10.1016/j.ijporl.2010.03.023

7. Pau BC, Ng DK: Prevalence of otitis media with effusion in children with allergic rhinitis, a cross sectional study. Int J Pediatr Otorhinolaryngol. 2016, 84:156-160. 10.1016/j.ijporl.2016.03.008

8. Bernstein JM: Role of allergy in eustachian tube blockage and otitis media with effusion: a review Otolaryngol Head Neck Surg. 1996, 114:562-568. 10.1016/s0194-5998(96)70247-4

9. Gates GA, Klein JO, Lim DJ, et al.: Recent advances in otitis media. 1. Definitions, terminology, and classification of otitis media. Ann Otol Rhinol Laryngol Suppl. 2002, 111:8-18. 10.1177/00034894021110s304

10. Korvel-Hanquist A, Koch A, Lous J, Olsen SF, Homoe P: Risk of childhood otitis media with focus on potentially modifiable factors: A Danish follow-up cohort study. Int J Pediatr Otorhinolaryngol. 2018, 106:19. 10.1016/j.ijporl.2017.12.027

11. Caylan R, Bektas D, Atalay C, Korkmaz O: Prevalence and risk factors of otitis media with effusion in Trabzon, a city in northeastern Turkey, with an emphasis on the recommendation of OME screening. Eur Arch Otorhinolaryngol. 2006, 263:404-408. 10.1007/s00405-005-1023-1

12. Homoe P, Kvaerner K, Casey JR, et al.: Panel 1: Epidemiology and Diagnosis. Otolaryngol Head Neck Surg. 2017, 156:1-21. 10.1177/0194599816643510

13. Jones LL, Hassanien A, Cook DG, Britton J, Leonardi-Bee J: Parental smoking and the risk of middle ear disease in children: a systematic review and meta-analysis. Arch Pediatr Adolesc Med. 2012, 166:18-27. 10.1001/archpediatrics.2011.158

14. Gultekin E, Develioglu ON, Yener M, Ozdemir I, Kulekci M: Prevalence and risk factors for persistent otitis media with effusion in primary school children in Istanbul, Turkey. Auris Nasus Larynx. 2010, 37:145-149. 10.1016/j.anl.2009.05.002

15. Rosenfeld RM, Schwartz SR, Pynnonen MA, et al.: Clinical practice guideline: tympanostomy tubes in children. Otolaryngol Head Neck Surg. 2013, 149:1-35. 10.1177/0194599813487302

16. Monasta L, Ronfani L, Marchetti F, et al.: Burden of disease caused by otitis media: systematic review and global estimates. PLoS One. 2012, 7:36226. 10.1371/journal.pone.0036226

17. Bluestone CD, Klein JO: Otitis Media in Infants and Children. PMPH-USA, New Haven, CT; 2007.

18. Norhafizah S, Salina H, Goh BS: Prevalence of allergic rhinitis in children with otitis media with effusion . Eur Ann Allergy Clin Immunol. 2020, 52:121-130. 10.23822/EurAnnACI.1764-1489.119

19. Chantzi FM, Kafetzis DA, Bairamis T, et al.: IgE sensitization, respiratory allergy symptoms, and heritability independently increase the risk of otitis media with effusion. Allergy. 2006, 61:332-336. 10.1111/j.13989995.2006.00971.x

20. Amani S, Khazraie HR: Relationship between serous otitis media and its risk factors in primary school students in Shahrekord. J Shahrekord Univ Med Sci. 2005, 7:33-38.

21. Lubianca Neto JF, Burns AG, Lu L, Mombach R, Saffer M: Passive smoking and nonrecurrent acute otitis media in children. Otolaryngol Head Neck Surg. 1999, 121:805-808. 